\title{
A safe and simple method of preserving right ventricular function during implantation of a left ventricular assist device
}

\author{
Matthias Loebe, MD, PhD, ${ }^{a}$ Evgenij Potapov, MD, ${ }^{b}$ Ralf Sodian, MD, ${ }^{b}$ Michael Kopitz, ${ }^{b}$ and George P. Noon, MD, ${ }^{a}$ \\ Houston, Tex, and Berlin, Germany
}

$\mathrm{R}$ ight-side heart dysfunction after left ventricular assist device (LVAD) implantation is a feared complication and is responsible for a substantial amount of postoperative morbidity and mortality. In addition to preoperatively existing right ventricular impairment, intraoperative damage caused by ischemia, volume overload, and increased pulmonary vascular resistance may all worsen the situation. Most recently, Adamson and colleagues ${ }^{1}$ presented a technique of right-sided heart reperfusion, which we have used on the basis of their suggestions for more than 2 years. ${ }^{2}$ This technique consists of transferring the aortic cannula to the pulmonary artery after the LVAD begins to support the left ventricle and cardiopulmonary bypass (CPB) has been reduced to $2 \mathrm{~L} / \mathrm{min}$ flow. The heart-lung machine then provides right ventricular support, and oxygenated blood is infused into the pulmonary circulation.

The procedure, however, carries the risk of a somewhat abrupt cessation of CPB support with hemodynamic depression and the potential of right ventricular overload between the time of removal of the aortic cannula until CPB through the pulmonary artery has been resumed.

Therefore, we have recently modified the procedure. Now, at the beginning of the implantation, a $24 \mathrm{~F}$ aortic cannula is placed in the usual fashion into the ascending aorta and connected to the arterial line. A second $24 \mathrm{~F}$ cannula is inserted into the pulmonary trunk and connected to the vent suction. The arterial line and vent suction lines are connected with additional tubing by means of $\mathrm{Y}$ connectors. This line is clamped during implantation (Figure $1, A$ and $B$ ). The LVAD is implanted with the heart beating, while blood is drained through the vent line connected to the pulmonary artery. After completion of the implant procedure, suction is halted, and the device is carefully deaired. When the LVAD is started and CPB flow can be reduced to $2 \mathrm{~L} / \mathrm{min}$, both the aortic cannula and the vent line are clamped, the connecting line is opened, and right-sided heart reperfusion is initiated (Figure 1,C). In this setting the left ventricle is supported by the LVAD, and the CPB supports the right ventricle.

From the Michael E. DeBakey Department of Surgery, Division of Assist Devices and Transplantation, Baylor College of Medicine, Houston, Tex, ${ }^{a}$ and the German Heart Institute Berlin, Berlin, Germany. ${ }^{\mathrm{b}}$

Received for publication March 23, 2001; accepted for publication April 2, 2001.

Address for reprints: Matthias Loebe, $\mathrm{MD}, \mathrm{PhD}$, Baylor College of Medicine, 6560 Fannin St, Suite 1860, Houston, TX 77030 (E-mail: mloebe@bcm.tmc.edu).

J Thorac Cardiovasc Surg 2001;122:1043

Copyright $\odot 2001$ by The American Association for Thoracic Surgery

$0022-5223 / 2001 \$ 35.00+0 \quad \mathbf{1 2 / 5 4 / 1 1 6 1 9 7}$

doi:10.1067/mtc.2001.116197

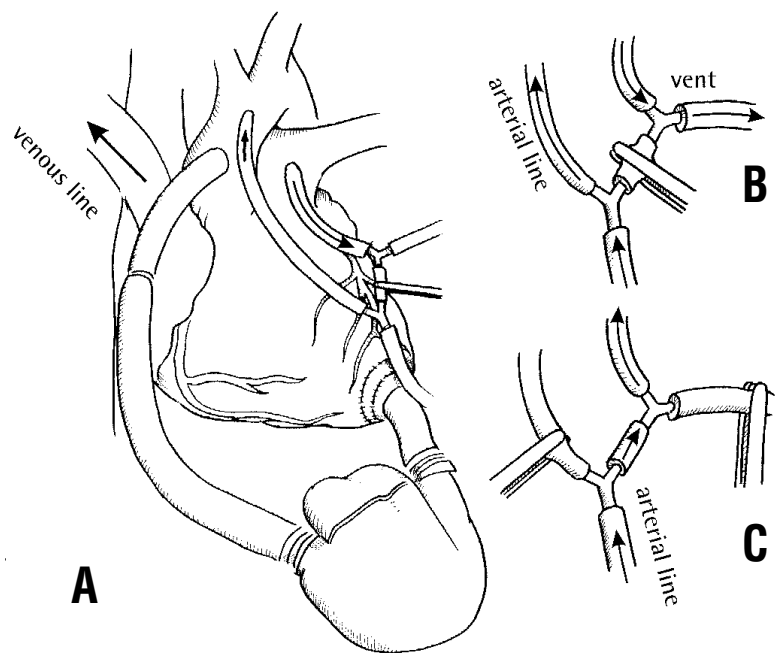

Figure 1. A, Total view of the tube setting of CPB for LVAD implantation. $B$, Tube setting of CPB during LVAD implantation. The connection between arterial line and pulmonary cannula is clamped, and the pulmonary cannula is used as the vent. C, Tube setting for right ventricular reperfusion after LVAD implantation. The aortic cannula is clamped, the connection between the arterial line and the pulmonary cannula is opened, and right-sided heart reperfusion is initiated.

During right-sided heart reperfusion, optimal LVAD function is adjusted, and medical therapy to support right ventricular function (including nitric oxide inhalation and catecholamine administration) is begun. On hemodynamic stabilization with normal electrocardiogram readings and central venous pressures below $10 \mathrm{~mm} \mathrm{Hg}, \mathrm{CPB}$ support is further reduced and finally discontinued.

This simple technique provides excellent right ventricular support after LVAD implantation. Weaning from CPB can be performed very smoothly under stable conditions without stressing the right ventricle. Since the introduction of the technique, we have implanted more than 30 LVADs at the German Heart Institute Berlin, without any mortality caused by right-sided heart failure.

The technique can also be used in heart transplantation or under other conditions in which preservation of optimal right ventricular function is essential. It is simple to implement and has proved to be very effective in our hands.

\section{References}

1. Adamson R, Dembitsky W, Daly P. Temporary isolated right ventricular bypass facilitates weaning left ventricular assist device patients from cardiopulmonary bypass [abstract]. ASAIO. 2000;46:203.

2. Loebe M, Drews T, Potapov E, Ngo DV, zu Dohna R, Hetzer R. Device selection in mechanical circulatory support. Perfusion. 2000;15:313-8. 